\title{
A teoria na prática é outra? Constituindo-se professoras de matemática dos primeiros anos do ensino fundamental
}

\author{
Maria Auxiliadora Bueno Andrade Megid*
}

\begin{abstract}
Resumo
O presente artigo traz considerações relacionadas a uma investigação realizada a partir da configuração de um grupo colaborativo que se reuniu durante um semestre para a discussão de aspectos relacionados ao ensino de matemática nos anos iniciais do Ensino Fundamental. Dele participaram a pesquisadora e duas professoras recém-egressas do curso de Pedagogia. Durante dez encontros e a partir da escrita e socialização de narrativas, foram discutidas e analisadas as práticas das professoras em seus primeiros anos de atuação após o término do curso. Verificou-se que o trabalho solitário e a falta de interlocutores no interior da escola, são empecilhos para que os aspectos estudados na Pedagogia estejam presentes nas ações docentes. A possibilidade de participação em grupo colaborativo fortalece as concepções das professoras relacionadas a como se ensina e a como o aluno aprende matemática, ampliando o repertório de práticas favorecendo o professor a sentir-se seguro em suas ações.
\end{abstract}

Palavras-chave: Formação de Professores; Ensino aprendizagem de matemática; Anos Iniciais do Ensino Fundamental.

\section{In practice, is the theory different? constituting mathematics teachers for the initial years of elementary} school

\begin{abstract}
This article presents considerations regarding an investigation that took place from the configuration of a collaborative group which had meetings during one semester for discussing aspects related to Math teaching in the initial years of Elementary School. This group was comprised of this researcher and two teachers who have recently started the Pedagogy course. During tem meetings and based on the written and socialized narratives, the teachers' practices in their first teaching years after concluding the course have been discussed and analyzed. It was possible to notice that the lonely work and the lack of an interlocutor inside the schools have been barriers for the aspects studied in Pedagogy to be practiced. The possibility of participating on collaborative groups strengthens the teachers' conceptions related to how to teach and how the students learn Math, which broadens the number of supporting practices for the teachers, making them feel more confident about their work.

Keywords: Teacher Education; Mathematics teaching and learning; Elementary School Initial Years.
\end{abstract}

\section{Introdução}

As pesquisas que temos realizado têm tomado como referência as ações de professores dos anos iniciais do Ensino Fundamental, visando investigar como os aspectos estudados durante a formação inicial relacionados ao ensino e à aprendizagem de matemática nos anos iniciais interferem nas práticas docentes.

O contato com egressos do curso de Pedagogia, quer por meio da atuação em grupos colaborativos, quer na troca de mensagens eletrônicas, indicam que o trabalho solitário praticado nas escolas, quando das primeiras experiências docentes, dificulta o desenvolvimento de ações semelhantes àquelas vivenciadas na formação inicial.

Traremos neste artigo, os resultados de uma pesquisa que teve por objetivo investigar as

* Endereço eletrônico: dmegid@ @uc-campinas.edu.br aproximações e os distanciamentos de uma proposta diferenciada desenvolvida em disciplinas do curso de Pedagogia direcionadas aos aspectos didáticos e metodológicos da matemática com as práticas docentes de professores dos anos iniciais nas ações subsequentes à formação universitária.

A investigação se desenvolveu a partir da elaboração e discussão de atividades exploratório investigativas que envolviam o ensino de matemática no interior de um grupo colaborativo configurado pela investigadora e duas professoras recém egressas do curso de Pedagogia, aqui denominadas por Luana e Ana. O referido grupo pode ser indicado como um grupo de estudo, de pesquisa-ação colaborativo.

Nas reuniões do grupo, problematizávamos as ações da sala de aula das professoras, discutíamos suas ações, planejávamos novas aulas, orientávamos os próximos procedimentos de aulas 
de matemática. Tais ações possibilitavam que as professoras refletissem sobre suas práticas e que a pesquisadora revisse suas ações enquanto formadora de professores que vão ensinar matemática para os anos iniciais do Ensino Fundamental.

Como anunciaremos ao final deste trabalho, a ação solitária no interior da escola, de maneira especial nos primeiros anos de docência, a falta de diálogo entre pares, dificulta a organização da ação pedagógica, de maneira especial aquelas referentes ao trabalho com a matemática. A participação num grupo colaborativo onde as discussões de tarefas escolares se faz presente, juntamente com a exposição das dificuldades e busca conjunta de superação, traz segurança aos professores iniciantes, permitindo-lhes enfrentar os desgastes iniciais da profissão e organizar estratégias de superação das dificuldades que o trabalho escolar oferece, de maneira especial no que diz respeito ao ensino de matemática para o Ensino Fundamental em suas séries iniciais.

\section{Saberes docentes e desenvolvimento profissional do professor: a teoria e a ação podem ser distinguidas?}

A proposta toma por pressuposto a organização de atividades de ensino de matemática planejadas pelas professoras e pela pesquisadora, no contexto de um grupo de estudo-pesquisa-e-ação colaborativo. A partir de discussões, orientações para planejamentos, leituras de aporte teórico, problematização e análises de aula, narrativas e socializações das mesmas, o desenvolvimento do trabalho colaborativo procurou proporcionar avanços na prática docente das professoras recém egressas do curso de Pedagogia, favorecendo a reflexão e a construção da prática docente.

A pretensão com tais ações era a de que as professoras pudessem refletir sobre as práticas iniciais da docência, no sentido de re-significar e potencializar seus saberes constituídos na graduação, bem como superar as limitações desses saberes. Buscamos refletir acerca das contribuições que a cooperação, num contexto de práticas reflexivas e investigativas podem trazer ao processo de constituição de professores dos primeiros anos do Ensino Fundamental em suas experiências docentes iniciais.

Procuramos compreender as dificuldades e conquistas das professoras em suas experiências iniciais de docência, no processo de construção de práticas docentes. Também buscamos verificar as aproximações e os distanciamentos que são encontrados entre os saberes construídos na formação inicial em Pedagogia e aqueles necessários para a prática docente, e em que medida os primeiros auxiliam na configuração dos segundos.

De acordo com as leituras realizadas e com as observações que temos feito no trabalho com professoras em diferentes ações de assessoria pedagógica em prefeituras de cidades do interior paulista, é possível afirmar que o envolvimento de professores iniciantes com os aspectos referentes à docência lhes confere uma dupla compreensão: por um lado, a importância da organização de saberes teóricos aprendidos em sua formação inicial, muitas vezes ainda não consolidados, referentes aos conteúdos que irão ministrar; de outro, à forma de utilizar tais conteúdos para que seja possível e significativa a aprendizagem de seus alunos.

Partimos do pressuposto enunciado por Cochran-Smith e Lytle (1999), de que a formação dos professores pode favorecer a mudança da escola. A escola é um espaço que necessita ser compreendido e colocado em debate. As autoras entendem não ser possível dividir o universo do conhecimento em conhecimento formal e conhecimento prático; indicam que se faz necessária a produção de conhecimentos a partir da própria sala de aula dos professores, a partir de investigações intencionais, considerando também teorias e materiais produzidos por outros, mas que são questionados e (re)interpretados.

Buscando adentrarmos nesse universo, configuramos um grupo colaborativo, com a participação da pesquisadora e duas professoras recém egressas do curso de Pedagogia. A professora Ana iniciava seu percurso docente, levando consigo apenas as práticas relacionadas aos estágios obrigatórios do curso. A professora Luana, como já tinha formação em nível do Ensino Médio (curso Normal, como denominado até o final dos anos 1990), já lecionava há aproximadamente dez anos. As ações durante os encontros tomaram como princípio básico o diálogo entre os participantes, a disposição de trocar experiências, de aprender, de comunicar-se.

Consideramos, de partida, que a aprendizagem é influenciada pela qualidade da comunicação que ocorre no ambiente onde os diálogos se estabelecem. Torna-se importante, nesse sentido, que o diálogo ocorra, favorecendo as relações interpessoais. A qualidade do diálogo relaciona-se à liberdade de aprender (FREIRE, 
1999). Há uma conexão entre a noção de diálogo e de conceitos referentes à emancipação, mesmo porque não há diálogo em condições de dominação. Diálogo, para Freire (1999), é o encontro entre pessoas que buscam conhecer e nomear o mundo. Nesse sentido, a ação e a reflexão, aliadas às atividades de investigação, favorecem o desenvolvimento do professor. Mas o diálogo será elemento fundamental nesse processo. AlrØ e Skovsmose (2006) apresentam, nesse contexto, o conceito de "atividades de aproximação". Nelas há a necessidade do estabelecimento de diálogo na ação. A aprendizagem, nessas atividades, é entendida como ação. Porém é importante destacar que nem toda ação remete à aprendizagem: algumas podem ser identificadas como atividades compulsórias. Como exemplo, os autores citam o ato de marchar dos soldados. Outra forma de aprendizagem pode ser designada como assimilação, como no caso da criança que aprende a falar, repetindo a fala de um adulto, mesmo não tendo a intenção de aprender a falar.

As ações nas reuniões do grupo configuravam-se a partir de um planejamento, da motivação, das decisões tomadas em conjunto; enfim, ancoravam-se numa intenção. Essa intencionalidade distinguia a aprendizagem de outras tantas ações feitas mecanicamente, isto é, não de forma inteiramente determinada, mas a partir das escolhas dos envolvidos. A aprendizagem em ação pressupõe envolvimento e uma situação em aberto. A intenção e a ação devem estar relacionadas, uma deverá estar presente na outra. Com isso, podemos dizer, como encontrado em AlrØ e Skovsmose (2006), que dois elementos básicos se fizeram presentes no decorrer da investigação: o envolvimento dos participantes e o processo aberto. Não há como predeterminar os resultados e as conclusões nos processos investigativos. De início, o convite para adentrar na ação do cenário de investigação deve pressupor que ele pode não ser aceito. A adesão a ele vai significar a possibilidade de uma cooperação investigativa, que vai denotar a qualidade da investigação.

$\mathrm{Na}$ reflexão a respeito da ação dos professores em seus trabalhos cotidianos, passo a apresentar, ancorada em Cochran-Smith e Lytle (2009), concepções relacionadas à dicotomia teoria e prática. Inicialmente, manifesto minha convicção de que as professoras parceiras desta pesquisa se constituem também investigadoras. Ancoramo-nos em Cochhran-Smith e Lytle (1999), indicando que as professoras em questão, buscaram assumir, durante a pesquisa, a investigação como postura ao descrever suas ações em sala de aula, ao discutir as estratégias utilizadas, ao relacionar seus conhecimentos adquiridos na graduação com os que desenvolviam em suas práticas docentes. E essa postura não se dava individualmente apenas, ou seja, cada qual em suas ações particulares. Tratavase de uma postura coletiva, das professoras e da pesquisadora.

Essa postura de investigação tem o compromisso com a melhoria da aprendizagem dos alunos. Para Cochran-Smith e Lytle (2009) ela se fundamenta nas ações e seus contextos, nos problemas da prática, e também na maneira como os professores que a exercem teorizam de forma colaborativa o ocorrido, refletem, estudam e agem sobre os problemas, na intenção de melhorar a aprendizagem, a vida dos seus alunos e da comunidade em que estão inseridos. E é nesse movimento que a pesquisa e suas relações dialéticas entre o pesquisador e professores, o conhecer e o fazer, as análises e as atuações, podem contribuir com essas práticas, muito menos causando dicotomias, mas produzindo mudanças dizimando os limites entre quem indica os problemas e quem lhes atribui soluções, conhecedores e seguidores.

Com essas convicções, entendemos que a relação da teoria com a prática deve ser mais profundamente discutida. Munir-se de conhecimento é também constituir práticas densas. Não existe, em nosso entendimento, boa prática ou boa teoria, se uma estiver alienada da outra. Uma e outra estão sim, imbricadas, confundem-se. O que se faz possível, quando tratamos de professores que investigam, refletem sobre a sua prática intenção de proporcionar a aprendizagem de seus alunos, se constitui em prática teorizada.

\section{Configuração Metodológica}

$\mathrm{Na}$ presente pesquisa instigamos as professoras recém egressas a escreverem narrativas envolvendo as ações que se configuravam nas suas práticas docentes e também nos momentos de encontros do grupo colaborativo, a partir do entendimento de que tal estratégia pode favorecer a melhor compreensão do que já sabem e do que podem construir através da ação de escrever.

A utilização do recurso de narrativas reflexivas no processo de ensino-aprendizagem docente constitui-se numa dimensão formativa e auxiliar ao desenvolvimento dos saberes docentes dos recém professores. Auxilia na busca de refletir e 
produzir conhecimentos a partir da questão que norteará a pesquisa.

A organização do grupo de professoras recém egressas ficou composta, ao final, por duas professoras e a pesquisadora. Destacamos que essas professoras cursaram disciplinas relacionadas ao ensino e à aprendizagem de matemática, por nós ministradas, o que proporcionou relacionar os componentes das disciplinas com as ações das professoras nesses anos subsequentes à sua formação. A partir da configuração do grupo e das propostas de trabalho, de maneira especial a escrita de narrativas, realizamos um estudo de caso coletivo com análises a partir de narrativas. Esta perspectiva metodológica tem por base os estudos de André (2005). Inicialmente, a autora traz as abordagens de Adelman et al (1980) para quem "um ponto em comum sobre o conceito de estudo de caso é que sempre envolve uma instância em ação" (p. 15). Na mesma obra, André (2005) também traz as contribuições de Stake (1994) que conferem um aspecto fundamental à esta perspectiva de pesquisa: "Segundo ele é o conhecimento do caso, ou melhor, o que se pretende ao estudar o caso" (ANDRÉ, 2005, p. 16).

Nesta pesquisa, ao investigar o caso das duas professoras recém egressas do curso de Pedagogia, configura-se o que Stake (1995) denomina de estudo de caso coletivo. Este ocorre "quando o pesquisador não se concentra num só caso, mas em vários, como por exemplo, em várias escolas ou vários professores, com finalidade intrínseca ou instrumental" (ANDRÉ, 2005, p. 20).

Outro aspecto metodológico por nós utilizado diz respeito às narrativas, tomadas como objeto de análise. As ações realizadas pelas professoras nas suas práticas docentes foram por elas expressas na busca de ganhar sentido por meio de relatos orais e escritos, a partir do que chamamos, com base em Suárez (2008), de práticas narrativas. Por meio desses relatos tornou-se possível a reconstrução de experiências vividas, nas quais buscamos (re) significar o vivenciado a partir de reflexões individuais e no grupo.

\section{As professoras e suas primeiras experiências após a graduação}

Passamos agora a apresentar as professoras parceiras desta investigação. Como já anteriormente anunciado, a professora Ana iniciava suas primeiras práticas docentes após a conclusão do curso de Pedagogia, não tendo anteriormente trabalhado nesta área. Já a professora Luana era mais experiente, uma vez que possuía formação para docência em nível de Ensino Médio. Trazemos de maneira mais detalhada, aspectos retirados das primeiras narrativas das professoras, relacionadas aos seus trabalhos docentes no início do ano de desenvolvimento da pesquisa.

Luana inicia indicando que atuou, nesta primeira experiência com o magistério, junto a uma turma de $3^{\circ}$ ano do Ensino Fundamental, numa escola municipal de uma cidade do interior paulista. Embora a escola não fosse muito grande, era a maior da cidade. Sua sala tinha 26 alunos, número considerado bom, uma vez que a média de alunos por classe era de 30 . Sentiu-se, nesta primeira experiência, muito perdida, não sabendo "por onde começar". Sentia-se ansiosa, com dificuldades em entender como os alunos aprendiam. De início fez uma sondagem para verificar o que os alunos já sabiam.

No que se refere aos conteúdos trabalhados, Luana desenvolveu com seus alunos o currículo geralmente utilizado nas escolas: os números naturais, sua utilização no contexto diário; o sistema monetário brasileiro; as operações aritméticas fundamentais; as formas geométricas; resolução de problemas. Indica que os alunos gostaram de trabalhar com jogos, muito embora, conforme afirma que utilizou poucas vezes esse recurso.

Retoma em seu relato uma prática comum no curso de graduação na disciplina Ensino Aprendizagem de Matemática. Ao invés de declarar se uma resolução estava certa ou errada, sempre inquiríamos: Como você pensou? A justificativa para isso era a de que os caminhos, no processo do ensino aprendizagem, são mais importantes do que o resultado. Desenvolver oralmente ou através de registro escrito o caminho mental realizado ajuda aquele que está respondendo a atividade a organizar as suas ideias, refletindo sobre o que fez e, em muitos casos, a perceber possíveis enganos. Para os demais que ouvem ou leem os registros, traz a possibilidade de adquirir estratégias diferentes das que conhecia, e também de contribuir com as produções do colega. Luana, que tinha vivenciado isso como aluna da graduação, agora experienciava isso com seus alunos.

No seu relato, traz diferentes registros de seus alunos e comenta que, tal qual vivenciado na graduação, solicitava que os alunos explicassem para a classe como haviam solucionado as situações problema que solicitava. Os mesmos procedimentos, de ouvir os seus alunos e instigá-los 
a contarem para o grupo classe como pensavam para solucionar as propostas de matemática, Luana utilizou na resolução das operações aritméticas, de maneira especial com a divisão. Conforme seu registro, ao mesmo tempo em que os alunos iam manifestando suas maneiras de resolver a operação, ela ia avançando, introduzindo novos conceitos e estratégias de cálculo.

No que se refere ao trabalho com os jogos, estratégia muito utilizada nas aulas da graduação, manifestou suas dificuldades:

Tive dificuldade de trabalhar com jogos, durante o ano trabalhei apenas seis vezes, com o "jogo nunca dez", principalmente pelo barulho em sala, o desrespeito às regras, ao colega e até brigas. Percebi que foi um material bastante importante para a aprendizagem dos alunos, mas quando pensava em trabalhar com jogos logo pensava nas brigas e no barulho e acabava desistindo. Além disso o município onde atuo utiliza o Sistema (...) de ensino (apostilado), que traz preparado os conteúdos a serem trabalhados e datas a serem cumpridas, dificultando o trabalho $e$ a ênfase de alguns conteúdos. Tínhamos que cumprir as páginas do livro integrado. Fazia atividades diversificadas e complementares, mas o conteúdo do livro deveria ser cumprido, prejudicando a autonomia pedagógica.

Segue indicando seu gosto por construir problemas a partir do raciocínio de seus alunos, de entender como pensavam, de produzir com eles tabelas e gráficos. Incentivava-os a partir da socialização das resoluções das duplas ou trios, comparando os resultados e os procedimentos. Embora pressionada pelo uso do material apostilado adotado no município, não deixava de lado as concepções adquiridas na formação: a importância de trazer as estratégias dos alunos para discussão, a elaboração de problemas, a busca de caminhos diferentes dos apresentados por autores dos manuais.

É possível inferir que Luana foi produzindo seus saberes e práticas docentes. A reflexão sobre a importância de respeitar os alunos em suas estratégias individuais, não perdendo de vista o compromisso de avançar com a aprendizagem deles, perseguiu Luana naquele ano letivo. A partir do relato da professora, fazemos uma relação com o que encontramos em Cochran-Smith e Lytle (2009): Luana passava agora a teorizar sua prática, no sentido de compreender como se fazia possível com seus alunos trabalhar a matemática a partir do vivenciado na formação inicial. De maneira mais específica, ela indica que entre os aspectos abordados no curso de Pedagogia, o que de mais importante ficou, se refere à valorização do raciocínio dos alunos. Assim relata:

O que utilizei com frequência foi valorizar o raciocínio dos alunos, buscando entender, através dos erros deles, a construção do conhecimento dos alunos, buscando aprender a ensinar melhor através dos registros realizados. (...) Mesmo quando o livro integrado trazia os algoritmos prontos, busquei valorizar a construção do conhecimento dos alunos. Nas atividades avaliativas que fazíamos, buscava entender o erro do aluno, entender e valorizar o que já sabia, o que foi construído e o que ainda precisava ser reforçado. (destaque da autora).

Luana nesta afirmação explicita sua intenção de, a partir da investigação das ações da aula, produzir seus conhecimentos docentes. E finaliza este registro inicial, indicando que no seu relatório do ano, que deveria ser entregue aos gestores da sua escola, recorreu ao material utilizado no curso de Pedagogia: "Fazendo algumas leituras percebi que o estudo fica mais claro e significativo depois de passar pela real experiência de professora, a preocupação de ensinar, de que realmente os alunos aprendam". Esta afirmação da professora nos faz perceber que ela não abandonou o vivido e estudado na graduação. Ao contrário, buscou re-significar as leituras e práticas na perspectiva de configurar sua ação docente num movimento de investigação e de reflexão.

Passamos agora a trazer os relatos da professora Ana. Nesse ano que sucedeu sua graduação, teve sua primeira experiência de docência. Atuou numa escola estadual de Campinas com um terceiro ano, onde estavam matriculadas 32 crianças com idades entre 8 e 11 anos. Como enfatiza Ana, sua sala era a turma "H". Como sabemos, sendo " $H$ " a oitava letra do alfabeto, esta deveria ser uma das últimas classes de terceiro ano a ser formada naquela escola. Em geral, nessas turmas são colocados aqueles alunos 
que causam mais aborrecimentos às professoras $\mathrm{e}$ são deixados para atuarem com as novatas no ofício.

No início do ano, conforme solicitação da escola ocorreu uma sondagem do que as crianças sabiam sobre matemática, a partir de um ditado de números. Esse ditado se repetiu a cada dois meses e com os resultados dessa avaliação era montado um portfólio de cada aluno. A coordenação pedagógica argumentava que essas sondagens, juntamente com as avaliações oficiais a serem feitas durante $\mathrm{o}$ ano, poderiam indicar a aprendizagem dos alunos, seus avanços ou retrocessos em relação à matemática.

Ana indica que a primeira sondagem que fez com os alunos lhe trouxe um sentimento de tristeza e até de desespero. Muitas das crianças da turma de $3^{\circ}$ ano não conheciam números maiores que 90, e muitos deles apenas reconheciam aqueles até dez ou vinte. Surgiu então a primeira inquietação: as crianças passavam pela escola sem adquirir conhecimentos básicos, como reconhecer os números. $\mathrm{O}$ que fazer para que compreendessem as operações aritméticas básicas? As dúvidas, segundo seu relato, perseguiram-na por todo o ano. As dificuldades das crianças se faziam presentes em todas as áreas, mas principalmente no que dizia respeito à matemática. Como alternativas para avançar, começou a utilizar as ferramentas que lhe eram apresentadas pelas colegas professoras da escola e também aquelas que trouxera da graduação. Recorreu ao Material Dourado, às calculadoras, ao quadro numérico, aos jogos com dadinhos e também a brincadeiras que utilizavam os números. O material de apoio utilizado pela escola (esse material deveria ser utilizado por todas as escolas da rede pública do Estado de São Paulo) era o "Programa Ler e Escrever" (SÃO PAULO, 2010). Este programa configura-se em política pública do Estado de São Paulo direcionada aos anos iniciais do Ensino Fundamental com a intenção de promover a melhoria do ensino.

Da mesma forma que ocorria com Luana, havia na escola um controle sobre o uso do material de apoio, sobre o número de aulas destinadas a ele, ao foco que deveria ser abordado em cada conteúdo, sempre considerando o manual do professor. Nas reuniões pedagógicas, definiam o que deveria ser feito semanalmente. Ana relata que em muitos momentos sentia a falta de criar suas próprias estratégias, de configurar atividades específicas para a sua turma, que pudessem satisfazer as necessidades de seus alunos. Mas as demais professoras, sempre presas ao "Programa Ler e Escrever", dificultavam esses voos. Ainda assim Ana, mesmo sem autorização da coordenação, levava atividades diferenciadas para atender às dificuldades de seus alunos.

Um aspecto encontrado no registro de Ana diz respeito à pressão das colegas para que não se afastasse dos costumeiros hábitos da escola, que não utilizasse recursos muito diferenciados. Essa pressão, sobretudo da coordenação da escola, principalmente no que se refere ao uso do material pedagógico adotado (sistema apostilado numa escola e o Programa Ler e Escrever naoutra), foi vivenciado tanto por Ana quanto por Luana.

\section{Os encontros do grupo}

Durante a investigação realizamos dez encontros do que indicamos ser o nosso grupo colaborativo. Tomamos aqui as concepções de Ibiapina (2008) a esse respeito. A autora indica que colaboração implica em negociação de conflitos próprios do ensino e da aprendizagem, o que pode demandar formas de superação das dificuldades e também a tomada de decisões democráticas. A mesma autora nos traz ainda que a interação de docentes e pesquisadores favorece a construção de teorias relacionadas às práticas ao negociarem crenças e valores, no movimento de compreender a questão de investigação. As ações dos professores influenciaram o processo da pesquisa e produziram a prática colaborativa.

E em decorrência disso, há o favorecimento das duas dimensões da pesquisa em educação: a construção de saberes e a formação contínua de professores (IDEM, p. 21). Buscando trazer aspectos dos encontros do grupo que corroboram com tais afirmações, traremos as concepções das professoras sobre as permanências da formação durante a graduação na ação da docência e as contribuições do grupo que se manifestaram como ações de formação continuada.

No que se refere ao primeiro aspecto, as concepções das professoras sobre as permanências da formação durante a graduação na ação da docência, Ana reafirma as suas dificuldades, relacionadas ao seu primeiro ano de docência. As novas experiências não expressavam a idealização que fazia delas. Na intenção de acompanhar seus compromissos, foi assumindo posturas diferentes daquelas que inicialmente tinha determinado. A seguir, apresentamos seus relatos: 
Muitas das coisas que aprendi na faculdade nas aulas de matemática abandonei neste início de carreira. Diante das pressões vindas da coordenação pedagógica, em prol de resultados satisfatórios, pressão psicológica em relação ao domínio de sala, dos conteúdos específicos que os alunos deveriam atingir. A inexperiência somada à insegurança no trabalho docente me levaram a caminhos tortuosos. Depois de quase quatro meses de aula percebi que muito do que ensinava os alunos não compreendiam, pois havia ensinado de uma forma tradicional, apresentando algoritmos prontos, pulando etapas essenciais da aprendizagem. Quando notei tudo isso, voltei atrás, retomei a matemática apreendida na Faculdade e vivenciada em minha prática como aluna e pesquisadora (se assim posso me chamar) sobre o ensino da matemática (Ana).

A necessidade de se sentir inserida no grupo novo onde atuava e as pressões dos gestores confundiam-na. E ainda, ao sentir-se sozinha, fragilizou-se, mesmo percebendo que a base inicial de formação era sólida. Mas o espírito de investigação não a abandonou e Ana retoma os procedimentos adquiridos na formação inicial, entendendo que seriam importantes para a aprendizagem das crianças.

Por outro lado Luana, quando realizou o curso de Pedagogia, já atuava como professora. Seus relatos indicam que suas práticas pedagógicas relacionadas à matemática foram sendo alteradas no percurso das disciplinas destinadas a esse conteúdo. E ainda tinha a oportunidade de, por vezes, realizar com seus alunos as atividades que vivenciava no curso, podendo trazer os resultados de sua sala de aula para ser comentado nos momentos da aula da graduação. O curso de Pedagogia, para Luana, funcionou não como "formação inicial", mas como formação em serviço ou continuada. Afirma que se sentiu fortalecida na mudança de suas práticas docentes, porque tinha o apoio da professora universitária.

Os dois depoimentos nos ajudam a refletir o quanto a possibilidade de discutir, em serviço as práticas pedagógicas, buscando alternativas de trabalho diferenciadas, mas tendo o apoio para essas mudanças, pode ser o fator relevante para a inclusão de outras práticas, que não as da repetição, da cópia, da educação bancária, nos procedimentos de matemática. Talvez se Ana tivesse tido a mesma oportunidade que Luana, mesmo sendo sua primeira experiência docente, não tivesse ficado insegura e pudesse utilizar, de maneira compartilhada com a professora universitária, os recursos encontrados na formação como pedagoga.

Analisando agora o segundo aspecto, as contribuições do grupo que se manifestaram como ações de formação continuada, iniciamos indicando que a disponibilidade das professoras em participar do grupo se deu de maneira muito importante. Apesar de seus compromissos e dos horários noturnos que dispúnhamos para os encontros, vinham com toda a disposição e, conforme a conversa se desenrolava, a participação se ampliava. Infelizmente os encontros foram em menor número do que aquele que supúnhamos inicialmente, mas foram relevantes para todas nós. A seguir, trazemos os relatos das professoras:

Apesar dos encontros em conjunto serem poucos foram muito significativos, pois percebo que nós professores não temos este tempo para refletir sobre a nossa prática e também sobre como o aluno aprende. Avaliar as estratégias que os alunos realizam, pensar e perguntar a eles como chegaram aos seus resultados, repensar outras estratégias de ensinar, fazem do encontro uma necessidade que proporciona bons resultados e um progresso em minhas práticas escolares (LUANA).

Ana considerou a importância dos encontros, como de um espaço onde as inquietações podiam ser expostas e onde todos buscavam as saídas em conjunto. Para ela, "os encontros propostos pela professora universitária fortaleceram a caminhada, nos enfrentamentos que a docência nos exige, também na confiança do meu trabalho".

Sobre as trocas de ações que ocorreram nos encontros, Luana destaca a importância das ponderações também da colega Ana:

Ouvir a minha colega Ana, suas estratégias de ensino e seu amor pelos alunos também me motivaram a seguir em frente, continuar estudando maneiras de aprender melhor a ensinar. Contudo, percebo que a oportunidade de falar de forma livre, sem olhares de repressão e pré julgamentos sobre conteúdos, materiais didáticos, datas estabelecidas e metas a serem compridas 
em relação aos conteúdos programados, além das dúvidas que temos em ensinar determinado assunto $e$ as novas ser proporcionada a todos os profissionais da Educação.

Ana concorda com Luana e destaca que essa liberdade de expressar-se, sem precisar preocupar com o julgamento do outro, permite que todas as inquietações venham à tona. A esse respeito compreendemos que os espaços escolares deveriam trazer essas alternativas para os professores. Ana ainda destaca:

Falar sobre as dificuldades minhas como professora, não é fácil, pois demonstro minhas fraquezas. No entanto consigo refletir sobre elas de uma forma mais tranquila quando percebo que as dificuldades aparecem não apenas em mim, nos meus alunos. Mais do que isso, elas podem ser usadas para romper barreiras.

Muito mais que momentos de informes, as reuniões pedagógicas deveriam ser tempos de estudo, de discussão dos problemas das salas de aula, das possibilidades de avanços que são encontrados nos momentos de contato com as crianças, por todos os professores. Sobre as atividades elaboradas em conjunto, Luana assim avalia:

A reflexão proporcionada pela elaboração de atividades a serem desenvolvidas pelos alunos e posteriormente discutidas em nosso grupo, possibilitou transitar por uma via de mão dupla. Quando discutíamos a natureza da atividade a ser realizada, já nos propúnhamos a levantar hipóteses acerca do conhecimento do aluno e do nosso domínio conceitual metodológico.

Para as professoras, essa reflexão as acompanhava no momento da aplicação das mesmas, no trabalho com as crianças. Luana assim relata: "Esta reflexão se estendia durante o desenrolar das atividades, seja na sala de aula com as crianças, seja na reflexão mediada pela pesquisadora, por meio da partilha do encaminhamento do conteúdo abordado em cada uma das classes". As professoras ainda comentam que, embora existam iniciativas esparsas na tentativa de ampliar as discussões do que acontece na sala de aula, elas ainda chegam muito timidamente, quando chegam, nos espaços escolares, onde a educação se desenvolve. E, no que se refere à matemática, parece que isto se dá mais timidamente. As professoras avaliam da mesma forma. Luana afirma que há muitos anos essa história de uma matemática difícil e para poucos foi e continua sendo reafirmada.

Apesar de iniciativas como esta [participação no grupo colaborativo], a escola ainda está distante de conseguir parcerias eficazes em seu interior, que sejam capazes de elevar o nível de ensino de maneira significativa, pois na maioria da vezes estas iniciativas esbarram tanto na estrutura do ensino, como na própria formação do professor (ANA).

As professoras demonstram também a mesma intenção da pesquisadora: que os espaços escolares se abram para as discussões da sala de aula e que os pesquisadores se voltem para os espaços da escola, a fim de compreenderem o que lá ocorrem, ouvindo os professores, as crianças, os gestores, sendo parceiros da escola, aprendendo, trocando os saberes relacionados à docência.

\section{Considerações sobre a investigação realizada}

Entendemos como muito significativo o processo de pesquisa percorrido por nós. Os encontros, não só proporcionaram as trocas de ações da sala de aula, aproximando aquela realidade da pesquisadora e permitindo que as professoras pudessem se ver nas experiências da outra, como também possibilitaram retomadas de ações vividas pelas professoras e pela pesquisadora, em situações diferenciadas, no âmbito da Graduação.

Para as professoras, a retomada de alguns conceitos estudados, trazendo a intenção e a segurança de trabalharem a partir de novas posturas. O grupo, a discussão de estratégias, permitia que avançassem nas incertezas e voltassem seguras, inclusive, para argumentar junto aos coordenadores e gestores, as posturas diferenciadas que tomavam com suas classes. Para a pesquisadora, foi importante compreender, através das afirmações das professoras, que ocorrem aproximações relacionadas ao que foi abordado nas disciplinas de matemática no curso de Pedagogia. Porém há necessidade de trazer para as aulas "casos de ensino", onde as professoras em formação se vejam 
confrontadas com alguns dos diferentes aspectos com os quais irão se defrontar na ação docente.

Foi possível perceber que as professoras que atuaram na pesquisa tinham características fundamentais para a docência: são investigadoras; exercem criticamente a docência; possuem em suas práticas uma característica que denominaremos de natureza inclusiva, uma vez que buscam que todos aqueles que se fazem presentes em suas aulas sejam de alguma maneira inseridos no contexto de aprendizagem ali proposto; avaliam com frequência os resultados das ações da sala de aula, propondo novas ações quando não percebem que seus objetivos de aprendizagem foram alcançados; e, sobretudo, buscam com frequência aprofundar seu desenvolvimento profissional, através de leituras e de participação em discussões com os pares.

Por fim, com as reflexões produzidas a partir das análises aqui trazidas, entendemos como necessário e urgente tanto repensar o curso de Pedagogia, em suas disciplinas destinadas à abordagem da matemática quanto aos processos de planejamento e de organização de reuniões pedagógicas no interior das escolas. No que se refere ao curso de Pedagogia, buscar considerar de forma enfática as ocorrências da sala de aula dos anos iniciais, o repertório real que lá é encontrado. Talvez trazendo os episódios vivenciados nos estágios realizados pelos alunos para discussão durante as aulas. E, no que se refere às escolas, organizar espaços de trocas, onde o respeito pelas individualidades, quer nas suas dificuldades, quer nas suas capacidades de produção, se façam presentes e discutidos.

Grupos colaborativos como os vivenciados nesta investigação, podem ser configurados mesmo no interior das escolas. $\mathrm{E}$ há profissionais, interessados pela educação, estudiosos da educação matemática, que podem fazer parte desses grupos. Assim, respondendo à pergunta título deste artigo A teoria na prática é outra? - indicamos que os conhecimentos adquiridos e elaborados nos cursos de formação inicial são necessários e úteis ao trabalho pedagógico. Mais do que isso, têm estreita relação com a prática docente. As dificuldades que se estabelecem dizem respeito às condições (ou a falta delas) encontradas pelos professores em seus ambientes de trabalho.

\section{Referências}

ALRØ, Helle; SKOVSMOSE, Ole. Diálogo e aprendizagem em Educação Matemática. Belo Horizonte: Autêntica, 2006.

ADELMAN, C.; KEMMIS S.; JENKINS, D. Rethinking Case Study: Notes From the Second Cambridge Conference. In Helen Simmons (ed.). Topwards a Science of the Singular. Norwich, UK, 1980, p. 45-61.

ANDRÉ, Marli E. D. A. de. Estudo de caso em Pesquisa e Avaliação Educacional. Brasília: Liber Livro, 2005.

COCHRAN-SMITH, Marilyn, LYTLE, Susan. L. Relationships of knowledge and practice: teacher learning in communities. Review of Research in Education, USA, n. 24, p. 249-305, 1999.

Inquiry as stance: practitioner research for the next generation. New York: Teachers College Press, 2009.

FREIRE, Paulo. Pedagogia da autonomia: saberes necessários à prática educativa. São Paulo, Paz e Terra, 1999.

IBIAPINA, Ivana M. L. De Melo. Pesquisa colaborativa: investigação, formação e produção de conhecimentos. Brasília: Líber Livros Editora, 2008 .

SÃO PAULO (Estado), Secretaria da Educação. Ler e Escrever: guia de planejamento e orientações didáticas. Fundação para o desenvolvimento da educação. FDE, 2010.

STAKE, E.E. Case Studies In N. K. Denzin e Y. S. Lincoln (edit.) Handbook of Qualitive Research. SAGE Publications, 1994, p. 236-247.

SAGE Publications, 1995.

SUÁREZ, Daniel H. A documentação narrativa de experiências pedagógicas como estratégia de pesquisa-ação-formação de docentes. In: PASSEGGI, Maria da Conceição; BARBOSA, Tatyana M. N. Narrativas de formação e saberes biográficos. Natal: EDUFRN; São Paulo: PAULUS, 2008. p. 103-122. (Coleção Pesquisa (Auto)Biográfica - Educação). 
Sobre a autora:

Maria Auxiliadora Bueno Andrade Megid: Puc-Campinas. 